\title{
Development of a microscopic platform for real-time monitoring of biomolecular interactions
}

\author{
Yasuhiro Sasuga, ${ }^{1,2}$ Tomomi Tani, ${ }^{1}$ Masahito Hayashi, ${ }^{1}$ Hisashi Yamakawa, ${ }^{3}$ \\ Osamu Ohara, ${ }^{3,4,5}$ and Yoshie Harada ${ }^{1,2}$ \\ ${ }^{1}$ The Tokyo Metropolitan Institute of Medical Science, Bunkyo-ku, Tokyo 113-8613, Japan; ${ }^{2}$ Core Research for Evolutional Science \\ and Technology (CREST), Japan Science and Technology Agency (JST), Honcho, Kawaguchi, Saitama 332-0012, Japan; \\ ${ }^{3}$ Department of Human Gene Research, Kazusa DNA Research Institute, Kisarazu, Chiba 292-0818, Japan; ${ }^{4}$ Research Center for \\ Allergy and Immunology, RIKEN Yokohama Institute, Tsurumi-ku, Yokohama, Kanagawa 230-0045, Japan
}

\begin{abstract}
We developed a new microscopic platform for the real-time analysis of molecular interactions by combining microbead-tagging techniques with total internal reflection fluorescent microscopy (TIRFM). The optical manipulation of probe microbeads, followed by photo immobilization on a solid surface, enabled us to generate arrays with extremely high density ( $>100$ microbeads in a $25 \mu \mathrm{m} \times 25 \mu \mathrm{m}$ area), and TIRFM made it possible to monitor the binding reactions of fluorescently labeled targets onto probe microbeads without removal of free targets. We demonstrated the high performance of this platform through analyses of interactions between antigen and antibody and between small compounds and proteins. Then, recombinant protein levels in total cellular lysates of Escherichia coli were quantified from the association kinetics using antibody-immobilized microbead arrays, which served as a model for a protein-profiling array. Furthermore, in combination with in vitro synthesis-coupled protein labeling, we could kinematically analyze the interaction of nuclear factor $\kappa B(p 50)$ with DNA. These results demonstrated that this platform enabled us to: (1) monitor binding processes of fluorescently labeled targets to multiple probes in real-time without removal of free targets, (2) determine concentrations of free targets only from the association kinetics at an early phase, and (3) greatly reduce the required volume of the target solution, in principle to subnanoliter, for molecular interaction analysis. The unique features of this microbead-based microarray system open the way to explore molecular interactions with a wide range of affinities in extremely small volumes of target solutions, such as extracts from single cells.
\end{abstract}

[Supplemental material is available online at www.genome.org.]

The development of DNA microarray technology has enabled the successful probing of complex transcriptional networks on a genome-wide scale (Rhodes et al. 2002; Beltran et al. 2003; Zheng et al. 2004). In addition, various types of microarrays for monitoring molecular interactions have been developed (de Wildt et al. 2000; Zhu et al. 2001; MacBeath 2002; Wang et al. 2003). However, one critical concern with these conventional microarrays is their limitation to static analysis of molecular interactions. Because conventional microarray systems detect probe binding by quantitative end-point measurements after removal of unbound targets, they are not suited to either kinematic analysis of molecular interactions or to the analysis of interactions with high dissociation rates. A simple approach to address this concern is to monitor the molecular interactions in real-time. Another concern is the analysis of molecular interactions using very small samples. Proteins and/or nucleic acids from a selected subpopulation of cells or even from a single cell can be extracted using new technologies such as laser capture microdissection (Paweletz et al. 2001), microfabricated fluorescence-activated cell sorting (Wang et al. 2005), and other microfluidic systems (Thorsen et al. 2002; Hong et al. 2004). More importantly, recent progress in bioimaging (Sako et al. 2000; Itoh et al. 2002; Murakoshi et al. 2004; Michalet et al. 2005), allowing the study of the

${ }^{5}$ Corresponding author.

E-mail ohara@kazusa.or.jp; fax 81-438-52-3914.

Article published online ahead of print. Article and publication date are at http://www.genome.org/cgi/doi/10.1101/gr.4235806. dynamic behavior of various proteins in living cells, has increased the need to bridge the gap between bioimaging and biochemistry at the single-cell level. Although DNA microarray technology can achieve mRNA profiling at a single-cell level by artificially amplifying target molecules by in vitro enzymatic reactions, such an approach is not robust and, more seriously, cannot be applied to proteins. A simple approach to address this is to miniaturize the molecular detection platform to the size of a single animal cell.

While real-time monitoring of binding processes and extreme miniaturization of the analysis platform are independent issues, it was our intention to address both of these issues for application to single-cell biology. Here we describe the development of an array-based real-time system using fluorescence imaging technologies for analyzing molecular interactions with extremely small amounts of target molecules. This analysis platform will make it practical to analyze multiple molecular interactions in parallel using subnanoliter samples.

\section{Results}

Outline of molecular-interaction analysis using fluorescence microscopy

To build a miniaturized array-based real-time analysis system, we selected a microscopic platform based on fluorescence imaging technology. A schematic view of our molecular interaction- 
monitoring platform is shown in Figure 1A. This system was based on an array of microbeads conjugated with different probes on a glass coverslip. A solution containing fluorescence-labeled target molecules is injected onto the microbead array and the binding of target molecules to the probes is monitored by total internal reflection fluorescence microscopy (TIRFM). Since evanescent excitation selectively illuminates only fluorophores very close to the glass surface (within $\leq 150 \mathrm{~nm}$ ) (Funatsu et al. 1995; Axelrod 2003), it is possible to track the binding reaction of the target molecules to the probe microbeads with a high signal-tobackground noise ratio and without removal of the target molecules in solution. The fluorescence of the microbeads is monitored in real-time by a CCD camera with an image intensifier.

\section{Microbead array fabrication}

Because the illumination area in objective lens-assisted TIRFM is restricted to a circular area with a diameter of $60-100 \mu \mathrm{m}$, we fabricated microbead-based arrays to fit this area using optical trapping followed by photo-cross-linking onto a glass surface. The fabrication procedures for microbead arrays are schematically shown in Figure 1, B and C. The advantages of this approach over direct immobilization of probes onto a glass surface are (1) high spatial resolution, (2) higher density of probes molecules on the microbeads, and (3) high-fabrication reproducibility because
A

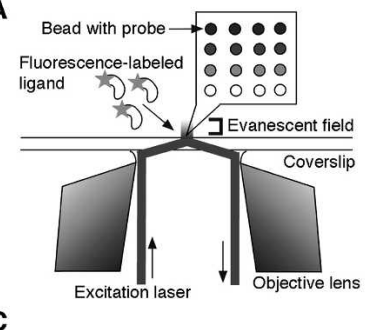

C

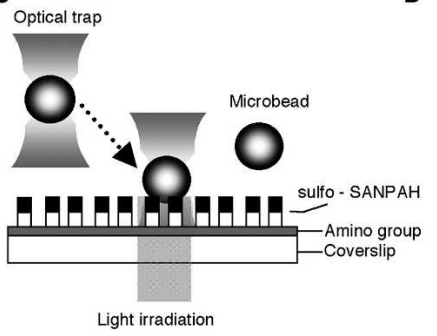

B

D

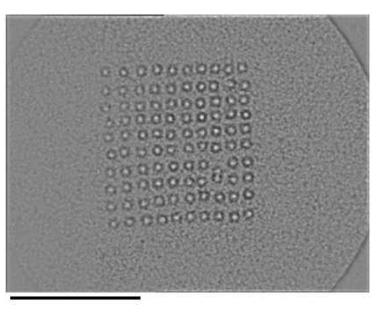

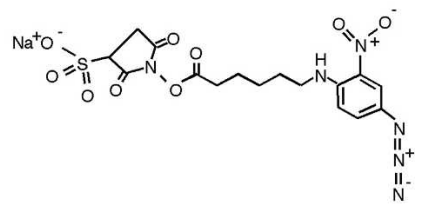

Figure 1. Molecular interaction analysis using a microscopic platform. $(A)$ Schematic drawing of the imaging strategy for detection of the molecular interactions. Proteins, nucleotides, or other biomolecules are immobilized onto the surface of microbeads, and the microbeads are arrayed on a glass coverslip. A solution containing fluorescently labeled target molecules is injected into the microbead array and the fluorescence, which binds to probe molecules on the surface of microbeads, is observed by objective lens-type total internal reflection fluorescence microscopy. (B) The chemical structure of sulfo-SANPAH (sulfosuccinimidyl 6-[4'-azido-2'-nitrophenylamino] hexanate). Bifunctional cross-linking reagent, sulfo-SANPAH, has NHS ester and nitrophenyl azide, which react with amino groups and is activated by the light irradiation, respectively. (C) Schematic diagram of microbead array fabrication. The amino group coated coverslip is conjugated with sulfo-SANPAH by its NHS ester. A microbead is captured by using an optical trap and carried to the fixing position. In the final step, the area where the microbead was carried is activated by light irradiation $(300-360 \mathrm{~nm}$ ) and the microbead is fixed at this position. (D) Microscopic image of a microbead array. The $100 \mathrm{mi}-$ crobeads $(10 \times 10$ pattern) arrayed on a coverslip are shown. The mean diameter of microbeads was $0.95 \mu \mathrm{m}$. Scale bar, $20 \mu \mathrm{m}$.
A

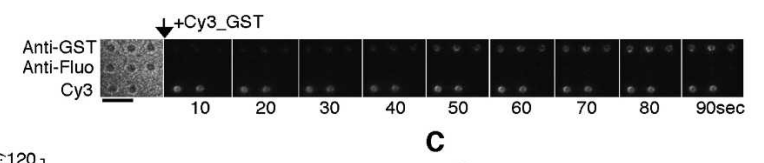

B

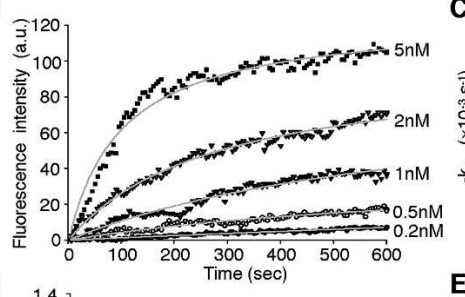

D
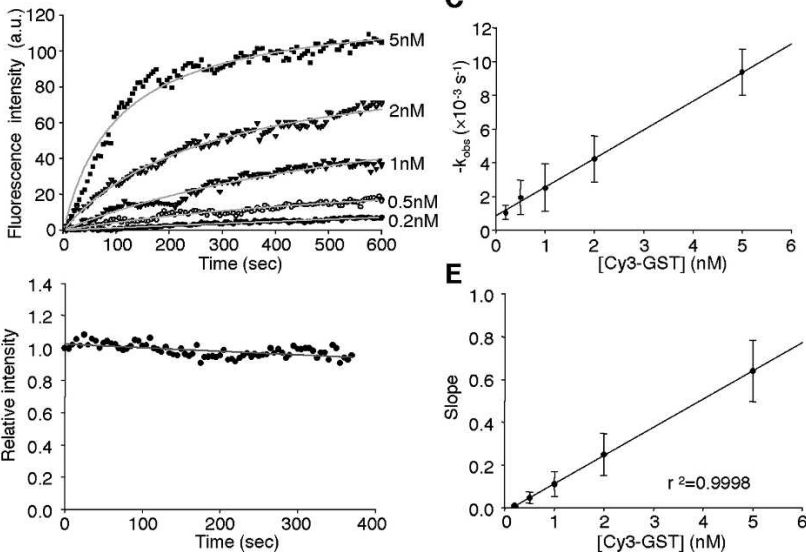

$E$

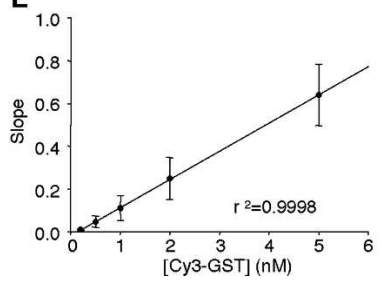

Figure 2. Analysis of antigen binding to antibody. (A) Microscopic images showing the binding of Cy3-labeled GST to the antibodyconjugated microbead array. Anti-GST and anti-fluorescein (fluo) antibody coated microbeads were arrayed on a coverslip, and Cy3-labeled GST (2 nM) was injected. (Left) The bright-field image of antibodyconjugated microbead array and others show the Cy3-fluorescence images. Cy3-conjugated microbeads (Cy3) were used as a marker for fluorescence imaging. Scale bar, $5 \mu \mathrm{m}$. (B) Concentration dependence of the association of Cy3-labeled GST to anti-GST antibody. Various concentrations of Cy3-labeled GST were added to the antibody-conjugated microbead arrays. Images were collected at 5-sec intervals. The symbols represent the mean fluorescence intensities from six different microbeads. Gray lines represent the nonlinear fitted curves. (C) Plot of $-\mathrm{k}_{\text {obs }}$ against concentrations of Cy3-labeled GST. (D) Determination of dissociation rate constant of Cy3-labeled GST from anti-GST antibody. After monitoring the binding phase, the buffer without Cy3-labeled GST was replaced and the observation was continued. Relative fluorescence intensities of dissociation of Cy3-labeled GST from anti-GST antibodyimmobilized microbeads are shown. The symbols represent the mean relative intensities from six different microbeads. $(E)$ Plots of slope values in the initial association phase against concentrations of Cy3-labeled GST. Error bars represent standard deviation from the average observed value from six different microbeads at each concentration. Straight lines represent the fitted linear regressions.

the same batch of microbeads can be used for the fabrication of a huge number of arrays.

As an example, Figure 1D shows the array pattern of 100 polystyrene microbeads (diameter of $0.95 \mu \mathrm{m}$, bead-to-bead spacing in a range of $2 \mu \mathrm{m}$ ) within a $25 \mu \mathrm{m} \times 25 \mu \mathrm{m}$ area of a coverslip. Small microbead size and small pitch values are the keys to miniaturization and to meeting the requirements for parallel detection of more than 100 interactions using TIRFM.

\section{Analysis of the binding of antigen to antibody on microbeads}

In order to evaluate the performance and applicability of this new microbead-based array platform for the detection of molecular interactions, we first monitored the binding of glutathione S-transferase (GST) to anti-GST antibody. Anti-GST and antifluorescein antibody-coated microbeads were arrayed on a coverslip and Cy3-labeled GST (Cy3-GST) was applied as the target onto this platform. Cy3-GST bound readily to anti-GST antibodycoated beads, whereas no binding was observed to antifluorescein antibody-coated beads (Fig. 2A). The fluorescence intensity of the anti-GST antibody-coated microbead increased dose and time dependently (Fig. 2B). The analysis of the binding 
phase gave an association rate constant $\left(\mathrm{k}_{\mathrm{ass}}\right)$ of $1.7 \times 10^{6}\left(\mathrm{M}^{-1}\right.$ $\mathrm{s}^{-1}$ ) according to equation 1 (see Methods; Fig. 2C). The dissociation rate constant $\left(\mathrm{k}_{\mathrm{diss}}\right)$ of $2.2 \times 10^{-4}\left(\mathrm{~s}^{-1}\right)$ according to equation 2 (see Methods) was also determined directly from the dissociation phase of Cy3-GST (Fig. 2D). From these rate constants, the dissociation constant $\left(\mathrm{K}_{\mathrm{D}}\right)$ was calculated to be $1.3 \times 10^{-10}(\mathrm{M})$.

In the initial association phase (up to $\sim 150 \mathrm{sec}$; Fig. 2B), we noticed that fluorescence intensity increased linearly. Each plot was thus fitted with a line to estimate the slope values, which were plotted against the concentrations of Cy3-GST (Fig. 2E). The results indicated that the slope values increased proportionally with Cy3-GST concentration (regression fitting provided a correlation coefficient of 0.9998 ), implying that the correct antigen concentrations can be estimated only from the analysis of the early association phase.

\section{Detection of the binding of low-molecular-weight molecules}

Mass-sensing sensor chip analysis, e.g., with a surface plasmon resonance (SPR) detector, is frequently used for real-time monitoring of molecular interactions. One of the drawbacks of this technique is low sensitivity to binding of small molecules. In contrast to this, the detection sensitivity for target molecules in our monitoring platform should be, in principle, independent of their molecular mass. To check whether or not our platform is applicable to the analysis of low-molecular-weight molecules, we examined the bindings of glutathione (GSH) to GST. The fluorescence images were collected at video rates, since the binding reaction reached equilibrium very rapidly. While Cy3-GSH bound to GST-coated microbeads as expected, no binding was observed on streptavidin-coated beads (Fig. 3A). Figure 3B shows the time course of the binding of the Cy3-GSH to GST at several concentrations (50-500 nM) of Cy3-GSH. The $\mathrm{K}_{\mathrm{D}}$ value of Cy3GSH to GST obtained from these results was $1.3 \times 10^{-6}(\mathrm{M})$, which roughly agrees with those obtained in previous studies using ${ }^{35}$-labeled GSH or other GSH derivatives (Jakobson et al. 1979; McHugh et al. 1996). Thus, the microbead-based array platform enabled us to successfully monitor the binding of lowmolecular-weight molecules. If test samples have a low dissociation constant, such as biotin-streptavidin binding $\left(\mathrm{K}_{\mathrm{D}}, 10^{-15} \mathrm{M}\right)$, the detection limit of the sample concentration would become much lower than the GSH-GST interaction. In fact, in the case of the binding of Cy3-labeled biotin to streptavidin, we succeeded in detecting binding at $1 \mathrm{pM}$ of Cy3-labeled biotin (Fig. 3C).

\section{Application of microbead arrays for the quantification} of a specific protein in a complex protein mixture

The binding reaction of a single type of fluorescently labeled target onto microbeads was successfully monitored as described above. We then investigated whether we could detect specific targets among a large number of nontarget fluorescently labeled molecules, a crucial task when using our system for quantitative proteomics in an antibody-array format. As a model system, we measured the production levels of recombinant GST in Escherichia coli using an antibody-conjugated microbead array. A soluble fraction was recovered from the lysate of $E$. coli harboring an IPTG-inducible GST expression plasmid in the presence and absence of IPTG, and allowed to react with amino-reactive Cy3 dye. After removal of free Cy3 dye, the Cy3-labeled proteins (Fig. $4 \mathrm{~A})$ were then applied onto an antibody-conjugated microbead array. The increase in fluorescence intensity of anti-GST anti-

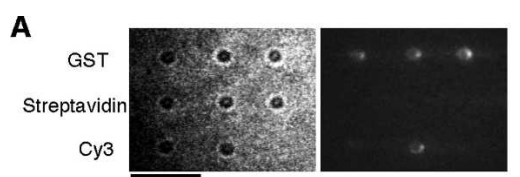

B

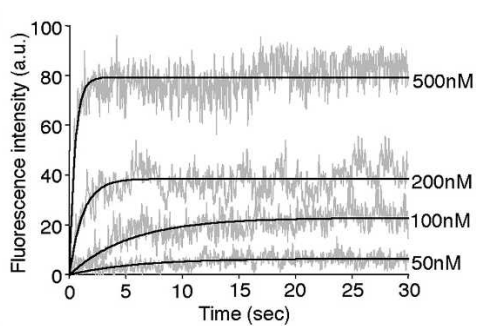

C

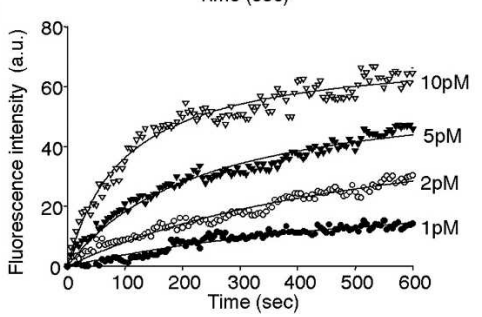

Figure 3. Analysis of the binding of low-molecular-weight molecules. GST and streptavidin coated microbeads were arrayed on a coverslip and the binding of Cy3-labeled GSH or biotin was monitored. (A) Microscopic images showing the binding of Cy3-labeled GSH to the proteinconjugated microbead array after the exposure to $200 \mathrm{nM}$ Cy3-labeled glutathione for $30 \mathrm{sec}$. (Left) The bright-field image; (right) the Cy3fluorescence image. Cy3-conjugated microbeads (Cy3) were used as a marker for fluorescence imaging. Scale bar, $5 \mu \mathrm{m}$. (B) Concentration dependence of the association of Cy3-labeled GSH to GST. Various concentrations of Cy3-labeled GSH were injected onto the proteinconjugated microbead arrays. Fluorescence images were collected at video rate. Gray lines represent the mean fluorescence intensities from three different microbeads. Black lines represent the nonlinear fitted curves. (C) The binding of Cy3-labeled biotin to streptavidin. Various concentrations of Cy3-labeled biotin were injected onto the proteinconjugated microbead arrays. Fluorescence images were collected at 5 -sec intervals. The symbols represent the mean fluorescence intensities from four different microbeads. Black lines represent the nonlinear fitted curves.

body-conjugated microbeads over time was found to be greater in the presence, than in the absence, of IPTG. On the other hand, there was no detectable fluorescence on the anti-fluorescein antibody-conjugated microbeads when lysates with and without IPTG induction were analyzed (Fig. 4B,C). From the association kinetics in the early phase ( $150 \mathrm{sec})$, the expression level of GST produced in the presence of IPTG was found to be four times higher than that in the absence of IPTG (Fig. 4D). These results were in essential agreement with that of protein blot analysis using the same samples and antibodies (Fig. 4E).

\section{Analysis of protein-DNA interactions using a fluorescently} labeled protein produced in vitro

In the experiments described above, a protein of interest was purified to homogeneity and then chemically labeled. In practical use, this could constitute a bottleneck in overall analysis and, more importantly, would greatly reduce the advantage of our platform, which requires only nanogram amounts of the labeled protein, whereas conventional biochemical purification techniques typically have yields in the microgram range. To address this issue, we took advantage of a cell-free translation system with fluorescently labeled puromycin (Nemoto et al. 1999; Mi-

\section{Genome Research}

www.genome.org 
Microbead array for molecular interaction analysis

A
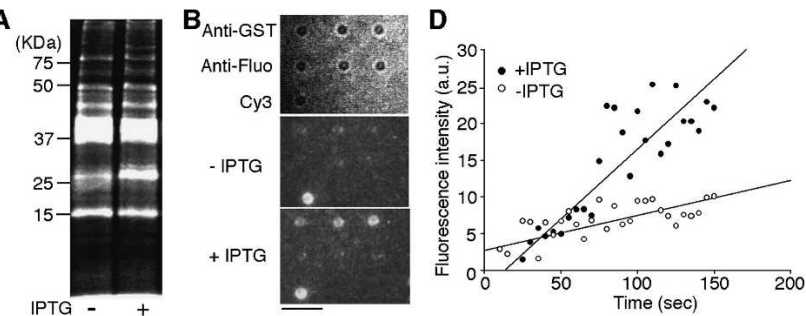

C
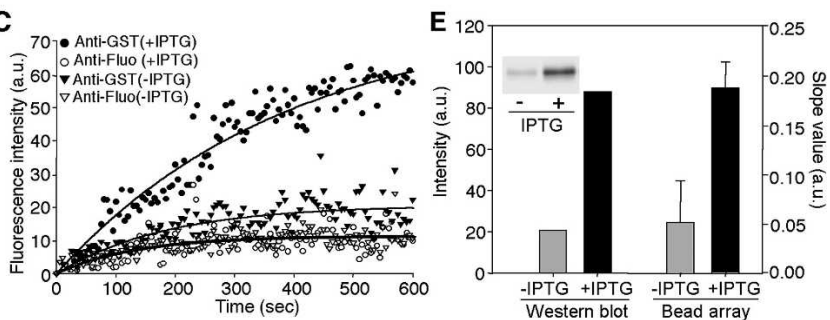

Figure 4. Analysis of protein expression levels in E. coli using antibodyconjugated microbead arrays. $(A)$ Cy3-labeled soluble proteins from two types of pGEX-transformed $E$. coli, one inducing by $1 \mathrm{mM}$ IPTG (+) and the other not $(-)$. Cy3-labeled soluble proteins were analyzed using $12.5 \%$ SDS-PAGE with a fluorescence imaging analyzer. The Cy3-fluorescence image is shown. (B) Microscopic images showing the binding of Cy3labeled soluble proteins to the anti-GST or anti-fluorescein (fluo) antibody-conjugated microbeads after the exposure to $20 \mathrm{nM}$ (in terms of Cy3 concentration; protein concentration, $0.1 \mu \mathrm{g} / \mathrm{mL}$ ) Cy3-labeled proteins for $600 \mathrm{sec}$. (Top) The bright-field image of an antibody-conjugated microbead array. (Middle, bottom) The Cy3-fluorescence images. A Cy3conjugated microbead (Cy3) was used as a marker for fluorescence imaging. Scale bar, $5 \mu \mathrm{m}$. (C) Time courses of the association of Cy3-labeled proteins with anti-GST or anti-fluo antibody. Fluorescence images were collected at 5-sec intervals. The data represent the mean fluorescence intensities from three different microbeads. The black lines represent the fitted nonlinear curves. $(D)$ Analysis of the binding of Cy3-labeled proteins to anti-GST antibody in the early association phase. The slope values in early association phase ( $150 \mathrm{sec})$ were obtained by a linear fitting procedure. ( $E$ ) Comparison of GST expression levels by Western blot analysis and antibody-conjugated microbead array analysis. Western blot analysis: Cell lysates were separated by $12.5 \%$ SDS-PAGE and analyzed with anti-GST antibody. The protein band intensities are shown. Bead array analysis: The slope values in the early association phase $(-150 \mathrm{sec})$ are shown. (Inset) A fluorogram of the Western blot. Error bars represent standard deviation from the average slope values observed from three different microbeads.

yamoto-Sato et al. 2000; Doi et al. 2002). Figure 5A shows a schematic drawing of the procedure for synthesis and analysis of the Cy3-labeled protein using the cell-free translation system. We tested whether this method could be used to analyze the interaction between the transcription factor, $\mathrm{NF}_{\kappa} \mathrm{B}$ p50, and doublestranded DNA. A single Cy3-fluorescent band of in vitro synthesized p50 with apparent molecular weight of $50 \mathrm{kDa}$ (Cy3-p50) was observed by SDS-PAGE (Fig. 5B). The concentration of Cy3p50 was estimated to be $480 \mathrm{nM}$ from the fluorescence intensity of the band. To analyze the binding kinematics of Cy3-p50 to the $\kappa B$ sequence (Ghosh et al. 1990; Kunsch et al. 1992), biotinylated double-stranded DNAs containing a consensus $\kappa \mathrm{B}$ sequence and control sequence with a 100-bp spacer sequence were bound to streptavidin-coated microbeads (Fig. 5C) and arrayed on a coverslip. The synthesized Cy3-p50 was applied to the DNAconjugated microbead array and binding to the DNA was monitored. Then, the solution with Cy3-p50 was replaced by the same buffer solution, but without Cy3-p50 and the observation was continued in order to monitor dissociation of Cy3-p50 from the beads. While Cy3-p50 bound to DNA strands containing а кB motif, no binding was observed in the case of control DNA (Fig. 5D,E). Association/dissociation rate constants were estimated by curve-fitting (George et al. 1995) based on kinetic interaction data of the binding of Cy3-p50 to the consensus $\kappa$ B sequence as $\mathrm{k}_{\mathrm{ass}}=4.2 \times 10^{6}\left(\mathrm{M}^{-1} \mathrm{~s}^{-1}\right)$ and $\mathrm{k}_{\text {diss }}=8.1 \times 10^{-4}\left(\mathrm{~s}^{-1}\right)$. This data is in agreement with the previous study measured by SPR analysis (Hart et al. 1999). Next, in order to analyze the binding characteristics of Cy3-p50 to the $\kappa \mathrm{B}$ sequence, several mutated $\kappa \mathrm{B}$ sequences were used (Fig. 6A). The results of the association and dissociation of Cy3-p50 and DNA-conjugated microbeads are

A
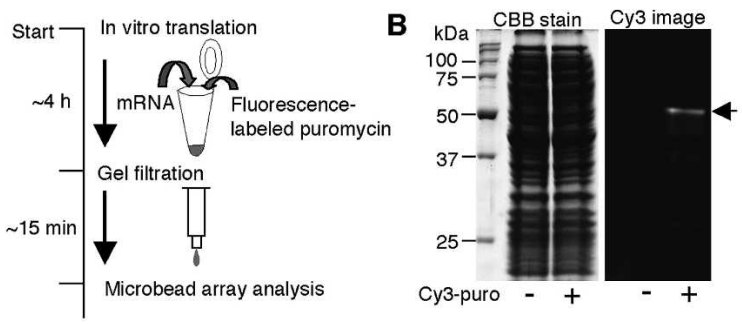

C
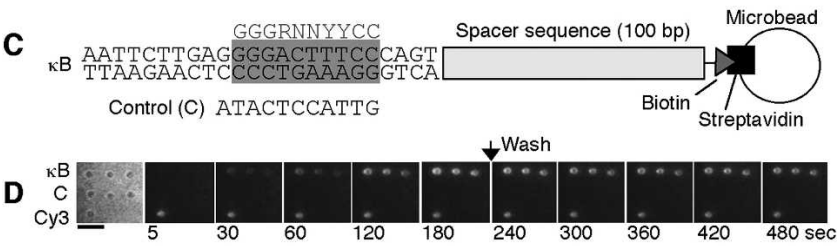

E

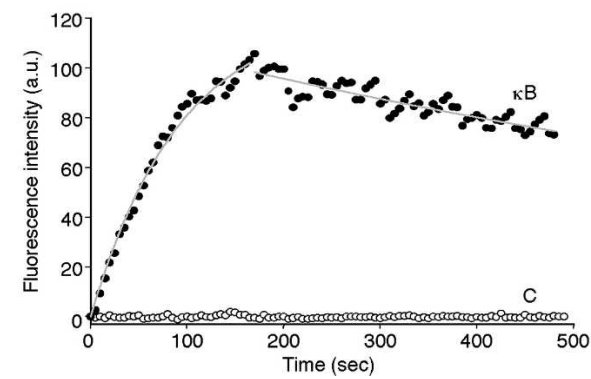

Figure 5. Analysis of protein-DNA interactions. (A) A schematic drawing of the procedure for the synthesis and the analysis of the Cy3-labeled protein using an in vitro translation system. The mRNA-encoding protein without a stop codon was added to the cell-free translation solution with fluorophore-conjugated puromycin. Unreacted puromycin was removed by gel filtration. The translated solution was applied to the microbead array without further purification. (B) Cy3-labeled NFkB p50. In vitro translation reaction was carried out in the presence of the template mRNA and $40 \mu \mathrm{M}$ Cy3-conjugated puromycin (Cy3-puro). The product was analyzed by $10 \%$ SDS-PAGE with a fluorescence image analyzer. After fluorescence detection, the gel was stained by CBB. (C) Target DNA-conjugated microbead constructions. Two types of DNA labeled with biotin were immobilized on the surface of streptavidin-coated microbeads, one containing a $\mathrm{\kappa B}$ motif $(\kappa \mathrm{B})$ and the other not (control). The gray box represents a $\kappa B$ motif and the gray letters indicate $\kappa B$ consensus sequence. In control DNA, the sequence of the gray box is replaced with the control sequence. $(D)$ Microscopic images showing the binding of Cy3-labeled NFKB p50 to the DNA-conjugated microbead array. Cy3labeled NFKB p50 (2 nM) was injected. (Left) The bright-field image of the DNA-conjugated microbead array and others show the Cy3fluorescence images. A Cy3-conjugated microbead (Cy3) was used as a marker for fluorescence imaging. After monitoring the association phase $(180 \mathrm{sec})$, the buffer without Cy3-labeled NFкB p50 was replaced and observation continued for the following $300 \mathrm{sec}$. Images were collected at 5-sec intervals. Scale bar, $5 \mu \mathrm{m}$. (E) Time courses of the association and dissociation of Cy3-labeled NFKB p50 to $\mathrm{\kappa B}$ or control DNA. The data represents the mean fluorescence intensities from three different microbeads. The gray lines represent the nonlinear fitted curves. 
A

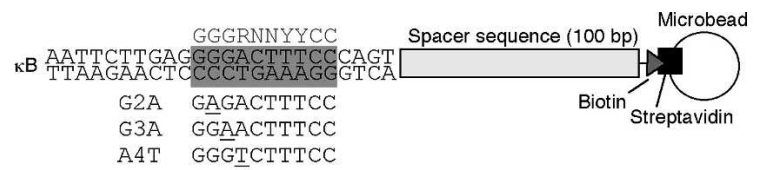

B

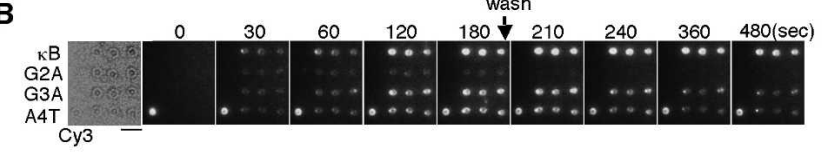

C
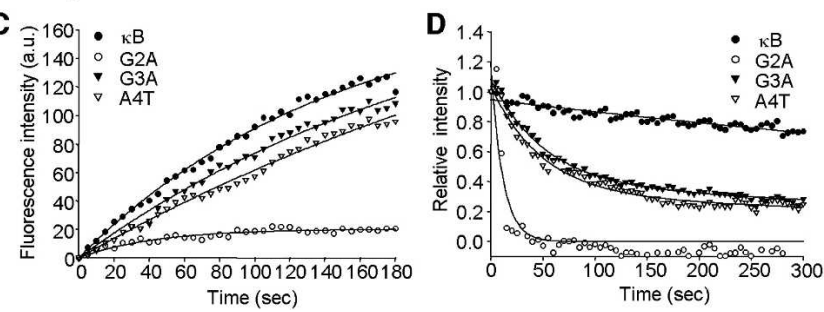

Figure 6. Parallel analyses of $N F \kappa B$ p50 bindings to $\kappa B$ sequence variants. $(A)$ Target DNA-conjugated microbead constructions. Four types of DNA labeled with biotin were immobilized on the surface of streptavidincoated microbeads, one containing a $\kappa B$ motif $(\kappa B)$ and the others containing single-nucleotide mutant sequences (G2A, G3A, and A4T). The gray box represents $a \kappa B$ motif and the gray letters indicate $\kappa B$ consensus sequence. In the mutant DNA, the sequence of the gray box is replaced with each single-nucleotide mutant sequence. The mutated position is underlined. (B) Microscopic images showing the binding of Cy3-labeled

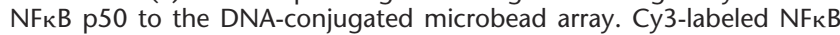
p50 (2 nM) was injected. (Left) The bright-field image of a DNAconjugated microbead array and the others show the Cy3-fluorescence images. A Cy3-conjugated microbead (Cy3) was used as a marker for fluorescence imaging. After monitoring the association phase (180 sec), the buffer without Cy3-labeled NFKB p50 was replaced and the observation was continued for the following $300 \mathrm{sec}$. Images were collected at 5 -sec intervals. Scale bar, $5 \mu \mathrm{m}$. (C) Time courses of the association of Cy3-labeled NFkB p50 to $\kappa \mathrm{B}$ or mutant DNA. The data represents the mean fluorescence intensities from three different microbeads. The black lines represent the nonlinear fitted curves. $(D)$ Time courses of the dissociation of Cy3-labeled NFкB p50 from $\kappa$ B or mutant DNA. The data represents the mean fluorescence intensities from three different microbeads. The black lines represent the fitted nonlinear curves.

shown in Figure 6, B,C,D, (see Supplemental Video). The $\mathrm{k}_{\text {diss }}$ values for single-nucleotide mutant variants were significantly higher than those of the consensus $к \mathrm{~B}$ sequence, whereas the difference in $\mathrm{k}_{\text {ass }}$ was small (Fig. 6D). The $\mathrm{k}_{\text {diss }}$ values for G2A, G3A, and A4T obtained were $8.9 \times 10^{-2}\left(\mathrm{~s}^{-1}\right), 8.8 \times 10^{-3}\left(\mathrm{~s}^{-1}\right)$, and $1.0 \times 10^{-2}\left(\mathrm{~s}^{-1}\right)$, respectively. In particular, the dissociation of p50 from G2A was 100 times higher than that of the wild-type $\mathrm{\kappa B}$ sequence. The results thus indicated that the guanosine on position 2 (G2) is extremely important for high-affinity binding of p50 to the $\kappa B$ sequence within the wild-type $\kappa B$ sequence, 5'-GGGACTTTCC-3'. This is consistent with previous findings from crystallography (Ghosh et al. 1995; Berkowitz et al. 2002) and DNA microarray-based studies (Wang et al. 2003). Our realtime analysis revealed for the first time that G2 played a crucial role in stabilizing the complex of p50 to the $\kappa \mathrm{B}$ sequence.

\section{Discussion}

In this study, we developed a novel platform for the detection of molecular interactions based on the combination of fluorescence imaging techniques with an ultra-dense microbead array assembled by optical manipulation. Using evanescent illumination for the detection of fluorescence-labeled target molecules, we succeeded in monitoring molecular interactions in real-time with high sensitivity, regardless of their molecular masses.

A combination of optical trapping of microbeads followed by photo-cross-linking enabled us to covalently fix microbeads onto a glass coverslip in any desired pattern. Because the density of this microbead array is 500-1500 times higher than the probe density in conventional microarrays (Lipshutz et al. 1999; Okamoto et al. 2000; Pellois et al. 2002), this platform is applicable, at least in principle, to sample volumes in the subnanoliter range, which is close to the volume of a single animal cell. If these microbeads are arrayed on the bottom of a picoliter-volume well (e.g., $20 \mu \mathrm{m} \times 20 \mu \mathrm{m} \times 20 \mu \mathrm{m}$ ), which is successfully connected to a microfluidic sample preparation module (Thorsen et al. 2002; Hong et al. 2004), our platform might offer a new approach for single-cell analysis. The sensitivity of this analysis platform is solely determined by the affinity between probe and target. For example, if we tried to detect the target molecules using an antibody array in a picoliter-volume well, the detection limit of the target molecules would be several hundred molecules per cell, since the detection limit of Cy3-labeled molecules using an antibody array is as low as $0.1 \mathrm{nM}$, as demonstrated in this study. This detection limit is considered to be low enough to monitor protein profiles of major proteins in a single cell.

Although microbeads have been used in various ways in microarray technology, the use of covalently immobilized microbeads on a glass surface is, to our knowledge, new. The microarray format described by Gunderson et al. (2004) is apparently similar to ours, but unlikely, in the current format, to be compatible with TIRFM. However, it is possible that in the future, the combination of their random arraying microbead technology with our photo-immobilization method might produce a TIRFMcompatible microarray system with a large number of microbeads. Their idea of decoding microbeads after random arraying might address the problem of fabrication throughput with our method. Another possible way of addressing this issue could be by using recently developed optical manipulation techniques that create a large number of optical traps using a computergenerated hologram (Curtis et al. 2002) and a Bessel beam (Garcés-Chávez et al. 2002). These techniques would allow trapping of multiple particles and reconfiguration with dynamic trapping patterns. If such a multiple trapping system were combined with a microfluidic bead sorter, such as a cell sorter, it might be possible to rapidly assemble a large number of probe beads.

A common concern with protein arrays is how to prepare probe proteins and targets. Since this concern is important to researchers, many groups have attempted to prepare a set of cDNAs that can produce all of the proteins encoded by the genome. This is conventionally called ORFeome cloning (Reboul et al. 2003; Vaglio et al. 2003; Brasch et al. 2004). If such a set of cDNAs becomes available, it would be straightforward to prepare probe microbeads, e.g., by self-assembling methods (He and Taussig 2001; Weng et al. 2002; Ramachandran et al. 2004). In the same way, the preparation of fluorescently labeled target proteins also becomes straightforward as demonstrated in this study (Figs. 5, 6), by using in vitro protein synthesis-coupled fluorescent labeling (Nemoto et al. 1999; Miyamoto-Sato et al. 2000; Doi et al. 2002).

In conclusion, we established a method for the generation of extremely high-density arrays based on the photoimmobilization of microbeads and confirmed that the resulting arrays could be successfully used for quantitative measurements of protein-protein, small compound-protein, and protein-DNA interactions in real-time. Our system has several unique features

\section{Genome Research}

www.genome.org 
compared with conventional molecular interaction monitoring systems, i.e., (1) requirement of only a subnanoliter-scale reaction volume for the interaction analysis, (2) highly sensitive and real-time monitoring of molecular interactions, and (3) parallel monitoring of multiple binding reactions. Together with novel microfluidic techniques for sample preparation, our approach has the potential to offer a basic tool for biological and medical applications that demand the parallel analysis of multiple molecular interactions in subnanoliter sample volumes.

\section{Methods}

\section{Fabrication of microbead array}

Washed coverslips $(24 \mathrm{~mm} \times 32 \mathrm{~mm}$, Matsunami glass) were treated with amino silane solution (5\% 3-aminopropyltriethoxysilane, $2.9 \% \mathrm{H}_{2} \mathrm{O}, 1 \mathrm{mM} \mathrm{HCl}$ in ethanol), which was polymerized overnight at room temperature. After washing with water and drying, a flow-cell was constructed from a bottom aminosilanized coverslip and a top coverslip $(18 \mathrm{~mm} \times 18 \mathrm{~mm}$, Matsunami glass), separated by two adhesive tapes (Nichiban). The chamber volume was about $10 \mu \mathrm{L}$. Sulfo-SANPAH (Pierce) solution $(0.01 \mathrm{mg} / \mathrm{mL}$ in $0.1 \mathrm{M}$ Na-phosphate buffer, $\mathrm{pH}$ 7.2) was poured into the flow-cell and incubated for $20 \mathrm{~min}$. After flushing with PBS buffer $(8000 \mathrm{mg} / \mathrm{L} \mathrm{NaCl}, 200 \mathrm{mg} / \mathrm{L} \mathrm{KCl}, 1150 \mathrm{mg} / \mathrm{L}$ $\mathrm{Na}_{2} \mathrm{HPO}_{4}, 200 \mathrm{mg} / \mathrm{L} \mathrm{KH}_{2} \mathrm{PO}_{4}$ ), the sulfo-SANPAH treated flowcell was incubated with blocking solution $(1 \mathrm{mg} / \mathrm{mL}$ dephosphorylated $\alpha$-casein [Sigma] in PBS buffer) for $15 \mathrm{~min}$. Protein or DNA-conjugated microbeads (see below) were placed into the flow-cell and a single microbead was captured by an optical trap. After moving to a fixing position, the microbead was put on the glass surface and illuminated with UV (300-360 nm) light for 1-5 sec. After fixing with UV light, free microbeads were washed away with PBS buffer. Then, microbeads coated with other test probes were injected, captured, and fixed one by one to create an array of heterogeneous spots. Microbeads were aligned and fixed at $2-5-\mu \mathrm{m}$ intervals.

\section{Preparation of probe-conjugated microbeads}

Protein A, streptavidin, and GST, respectively, were fixed to carboxylated polystyrene microbeads by a chemical cross-linking reaction (see Supplemental Methods). Antibody-conjugated microbeads were prepared as follows: Anti-GST (sc-459, Santa Cruz) or anti-fluorescein (Rockland) antibodies were first trapped on protein A-conjugated microbeads, and then cross-linked with protein A using $6.5 \mathrm{mg} / \mathrm{mL}$ DMP (Pierce) in $0.2 \mathrm{M}$ triethanolamine ( $\mathrm{pH}$ 8.2). DNA-conjugated microbeads were prepared as follows. The 128-bp DNA fragments carrying the NFkB-binding sequence, or its variant sequences, were prepared by PCR from the template plasmids using oligonucleotides (top strand, see Supplemental Methods) and a biotin-labeled oligonucleotide (biotin-5'-CTCGTATGTTGTGTGGAATTGTG-3'). The biotinlabeled PCR products $(50 \mathrm{ng} / \mu \mathrm{L})$ were captured on streptavidinconjugated microbeads to generate DNA probe microbeads.

\section{Fluorescent labeling of target molecules}

Purified GST was mixed with amino-reactive Cy3-dye (Amersham Bioscience) in a ratio of 1:3 in PBS buffer for $1 \mathrm{~h}$ at room temperature. Free Cy3-dye was removed by a NAP-5 column (Amersham Bioscience). The molar ratio of GST:Cy3 dye was 1:1. GSH and biotin-X-cadaverin, respectively, were labeled with $\mathrm{SH}$ reactive Cy3 dye (Amersham Bioscience) and amino-reactive Cy3 dye in a ratio of $1: 3$ for $2 \mathrm{~h}$ at room temperature. The Cy3-labeled GSH and biotin were purified by thin-layer chromatography
(TLC), as described by Wang et al. (2000) with slight modifications (see Supplemental Methods). Soluble proteins in E. coli expressing GST were labeled with Cy3-dye as follows: E. coli (DH5 $\alpha)$ transformed with pGEX $6 \mathrm{p}-1$ was cultured overnight at $37^{\circ} \mathrm{C}$. GST expression was induced with $1 \mathrm{mM}$ IPTG at $37^{\circ} \mathrm{C}$, and the cells were grown for another $30 \mathrm{~min}$. Cultured cells in the absence of IPTG were used as a control. One-milliliter cultures were disrupted by freeze-thawing. Aliquots of soluble fraction were labeled with amino-reactive Cy3-dye in PBS buffer for $30 \mathrm{~min}$ at room temperature. Unreacted Cy3-dye was removed by gel filtration with Sephadex G-25 (Amersham Bioscience) equilibrated with PBS buffer.

\section{Immunoblotting}

SDS gel electrophoresis was carried out using a $12.5 \%$ polyacrylamide gel. Cy3-labeled soluble proteins from E. coli either induced by IPTG or not, were electrophoretically transferred to Hybond PVDF membrane (Amersham Bioscience) and reacted with a primary rabbit polyclonal antibody against GST followed by a secondary antibody of horseradish peroxidase linked antirabbit IgG (Amersham Bioscience). The protein band of GST was detected with the ECL-plus detection system (Amersham Bioscience) and analyzed with ChemiDoc (Bio-Rad Laboratories).

\section{Synthesis and labeling of $\mathrm{NF}_{\kappa} \mathrm{B}$ p50 using a cell-free translation system}

One microgram of template plasmid (see Supplemental Methods) linearized with XhoI was transcribed in $20 \mu \mathrm{L}$ of T7 transcription $\operatorname{mix}$ (Promega) for $30 \mathrm{~min}$ at $37^{\circ} \mathrm{C}$. The transcript was purified by RNeasy (Qiagen). In vitro translation was carried out in Wheat Germ extract (Proteios, Toyobo) with $3 \mu$ g of template RNA in 25 $\mu \mathrm{L}$ of reaction mixture containing Cy3-puro (see Supplemental Methods) at a final concentration of $40 \mu \mathrm{M}$ for $4 \mathrm{~h}$ at $26^{\circ} \mathrm{C}$. Unreacted Cy3-puro was removed by gel filtration with Sephadex G-50 (Amersham Bioscience) equilibrated with PBS buffer. The translated solution was separated by SDS-PAGE, and the synthesized Cy3-p50 was confirmed by Molecular Imager FX (Bio-Rad Laboratories). The concentration of the labeled protein was determined from the values of fluorescence intensity compared with a known labeling ratio of purified Cy3-labeled protein.

\section{Microscope}

An inverted microscope (IX-70, Olympus) was modified to fit the microbead array platform. Nd:YAG laser (IRCL1000-1064, 500 $\mathrm{mW}$, CrystaLaser LC) and UV light from a mercury lamp sent through a pinhole (diameter $5 \mu \mathrm{m}$, PA-5, SIGMA KOKI), respectively, were used for the optical manipulation and the activation of sulfo-SANPAH. These laser and UV lights were shone into the microscope with the aid of optical filters and focused on the objective plane through the objective lens (UApo/340 40×, N.A. $=1.35$, Olympus). A 532-nm Nd:YAG laser (GCL-050-L, 500 $\mathrm{mW}$, CrystaLaser LC) was used for fluorescence excitation through the objective lens (PlanApo $100 \times$, N.A. $=1.40$, Olympus), and evanescent wave illumination was used. Excitation light intensity and exposure time were controlled by neutral density filters and a mechanical shutter. Bright-field and fluorescence images were captured by an EB-CCD camera (Hamamatsu Photonics) with an image intensifier (VS4-1845, VideoScope). The acquired images were recorded on DV-videotape using a videocassette recorder (DSR-11, Sony).

\section{Experimental protocols}

The following buffers were used: binding buffer I (10 mM HEPES, $150 \mathrm{mM} \mathrm{NaCl}, 3 \mathrm{mM}$ EDTA, 0.005\% Tween 20, $1 \mathrm{mg} / \mathrm{mL}$ dephos- 
phorylated $\alpha$-casein at $\mathrm{pH}$ 7.4) for analyses of GST, GSH, biotin, or soluble proteins; binding buffer II $(10 \mathrm{mM}$ HEPES, $150 \mathrm{mM}$ $\mathrm{NaCl}, 3 \mathrm{mM}$ EDTA, $0.005 \%$ Tween $20,1 \mathrm{mg} / \mathrm{mL}$ dephosphorylated $\alpha$-casein, $0.02 \mathrm{mg} / \mathrm{mL}$ poly [dI-dC] [Amersham Bioscience] at $\mathrm{pH}$ 7.4) for NFкB analysis. The Cy3-labeled targets were diluted with respective binding buffers. Just before observation, an oxygen scavenger system (Harada et al. 1990) was added to prevent fluorescence bleaching. After the fabrication of the microbead array, $10 \mu \mathrm{L}$ of the target solution was injected into the flow cell and the binding of Cy3-labeled targets with probe-conjugated microbeads was observed. After monitoring over specified periods of time, buffer without Cy3-labeled targets was injected using a peristaltic pump (205S, Watson-Marlow Bredel Pumps) at a flow rate of $100 \mu \mathrm{L} / \mathrm{min}$ to monitor the dissociation phase. Fluorescence images were collected every $5 \mathrm{sec}$ (exposure time of $1 / 8 \mathrm{sec}$ ) or video rate. All reactions were observed at $30^{\circ} \mathrm{C}$. The quantitative measurements of fluorescence intensity were performed with Meta Imaging Software (Molecular Devices).

\section{Data analysis}

Changes in curve-fitted fluorescence intensity (FI) value at the association phase were converted to a plot of FI versus time (t). The slopes of the $\mathrm{dFI} / \mathrm{dt}$-versus-FI plots represent the observed association rate, $-\mathrm{k}_{\mathrm{obs}}$. A plot of $-\mathrm{k}_{\mathrm{obs}}$ against a concentration of injected target allows $\mathrm{k}_{\mathrm{ass}}$ and $\mathrm{k}_{\text {diss }}$ to be determined from equation 1:

$$
-\mathrm{k}_{\mathrm{obs}}=\mathrm{k}_{\mathrm{ass}} \times \mathrm{C}+\mathrm{k}_{\mathrm{diss}}
$$

where $\mathrm{k}_{\mathrm{ass}}, \mathrm{k}_{\mathrm{diss}}, \mathrm{C}$ are the association rate constant, the dissociation rate constant, and the concentration of injected target, respectively. The $\mathrm{k}_{\text {diss }}$ can also be measured in the buffer without target after the observed association phase. Since the concentration of the target is zero, equation 2 describes first-order kinetics:

$$
\ln \left(\mathrm{FI}_{\mathrm{l}} / \mathrm{FI}_{\mathrm{n}}\right)=\mathrm{k}_{\text {diss }} \times \mathrm{t}
$$

where $\mathrm{FI}_{1}$ and $\mathrm{FI}_{\mathrm{n}}$ are the fluorescence intensities at the end of binding (time $t_{1}$ ) and at the time $t_{n}$, and $t$ equals $t_{n}-t_{1}$.

\section{Acknowledgments}

This work was supported in part by a research grant from Core Research for Evolutional Science and Technology (CREST) of the Japan Science and Technology Agency (JST), by a Grant-in-Aid for Scientific Research by the Ministry of Education, Culture, Sports, Science, and Technology of Japan (to Y.H.), and by the Human Frontier Science Program (to Y.H.). Y.H. also acknowledges the financial support from the Toray Science Foundation. We thank Dr. Toshiki Tanaka for his suggestion of purifying puromycin and Dr. Naoto Nemoto for his advice on the synthesis of amino-dC-puromycin.

\section{References}

Axelrod, D. 2003. Total internal reflection fluorescence microscopy in cell biology. Methods Enzymol. 361: 1-33.

Beltran, S., Blanco, E., Serras, F., Pérez-Villamil, B., Guigó, R., Artavanis-Tsakonas, S., and Corominas, M. 2003. Transcriptional network controlled by the trithorax-group gene ash2 in Drosophila melanogaster. Proc. Natl. Acad. Sci. 100: 3293-3298.

Berkowitz, B., Huang, D.-B., Chen-Park, F.E., Sigler, P.B., and Ghosh, G. 2002. The X-ray crystal structure of NF-кB p50.p65 heterodimer bound to the interferon $\beta-\kappa B$ site. J. Biol. Chem. 277: 24694-24700.

Brasch, M.A., Hartley, J.L., and Vidal, M. 2004. ORFeome cloning and systems biology: Standardized mass production of the parts from the parts-list. Genome Res. 14: 2001-2009.

Curtis, J.E., Koss, B.A., and Grier, D.G. 2002. Dynamic holographic optical tweezers. Optics Commun. 207: 169-175.

de Wildt, R.M., Mundy, C.R., Gorick, B.D., and Tomlinson, I.M. 2000. Antibody arrays for high-throughput screening of antibody-antigen interactions. Nat. Biotechnol. 18: 989-994.

Doi, N., Takashima, H., Kinjo, M., Sakata, K., Kawahashi, Y., Oishi, Y., Oyama, R., Miyamoto-Sato, E., Sawasaki, T., Endo, Y., et al. 2002.

Novel fluorescence labeling and high-throughput assay technologies for in vitro analysis of protein interaction. Genome Res. 12: 487-492.

Funatsu, T., Harada, Y., Tokunaga, M., Saito, K., and Yanagida, T. 1995. Imaging of single fluorescent molecules and individual ATP turnovers by single myosin molecules in aqueous solution. Nature 374: $555-559$.

Garcés-Chávez, V., McGloin, D., Melville, H., Sibbett, W., and Dholakia, K. 2002. Simultaneous micromanipulation in multiple planes using a self-reconstructing light beam. Nature 419: 145-147.

George, A.J.T., French, R.R., and Glennie, M.J. 1995. Measurement of kinetic binding constants of a panel of anti-saporin antibodies using a resonant mirror biosensor. J. Immunol. Methods 183: 51-63.

Ghosh, S., Gifford, A.M., Riviere, L.R., Tempst, P., Nolan, G.P., and Baltimore, D. 1990. Cloning of the p50 DNA binding subunit of NF-кB: Homology to rel and dorsal. Cell 62: 1019-1029.

Ghosh, G., Duyne, G.V., Ghosh, S. and Sigler, P.B. 1995. Structure of NF-кB p50 homodimer bound to a кB site. Nature 373: 303-310.

Gunderson, K.L., Kruglyak, S., Graige, M.S., Garcia, F., Kermani, B.G., Zhao, C., Che, D., Dickinson, T., Wickham, E., Bierle, J., et al. 2004. Decoding randomly ordered DNA arrays. Genome Res. 14: 870-877.

Harada, Y., Sakurada, K., Aoki, T., Thomas, D.D., and Yanagida, T. 1990. Mechanochemical coupling in actomyosin energy transduction studied by in vitro movement assay. J. Mol. Biol. 216: 49-68.

Hart, D.J., Speight, R.E., Cooper, M.A., Sutherland, J.D., and Blackburn, J.M. 1999. The salt dependence of DNA recognition by NF-кB p50: A detailed kinetic analysis of the effects on affinity and specificity. Nucleic Acids Res. 27: 1063-1069.

He, M. and Taussig, M.J. 2001. Single step generation of protein arrays from DNA by cell-free expression and in situ immobilization (PISA method). Nucleic Acids Res. 29: e73.

Hong, J.W., Studer, V., Hang, G., Anderson, W.F., and Quake, S.R. 2004. A nanoliter-scale nucleic acid processor with parallel architecture. Nat. Biotechnol. 22: 435-439.

Itoh, R.E., Kurokawa, K., Ohba, Y., Yoshizaki, H., Mochizuki, N., and Matsuda, M. 2002. Activation of Rac and Cdc42 video imaged by fluorescent resonance energy transfer-based single-molecule probes in the membrane of living cells. Mol. Cell. Biol. 22: 6582-6591.

Jakobson, I., Warholm, M., and Mannervik, B. 1979. The binding of substrates and a product of the enzymatic reaction to glutathione S-transferase A. J. Biol. Chem. 254: 7085-7089.

Kunsch, C., Ruben, S.M., and Rosen, C.A. 1992. Selection of Optimal $\kappa \mathrm{B} /$ Rel DNA-Binding motifs: Interaction of both subunits of NF- $\mathrm{B}$ with DNA is required for transcriptional activation. Mol. Cell. Biol. 12: $4412-4421$.

Lipshutz, R.J., Fodor, S.P.A., Gingeras, T.R., and Lockhart, D.J. 1999. High density synthetic oligonucleotide arrays. Nat. Genet. Suppl. 21: 20-24.

MacBeath, G. 2002. Protein microarrays and proteomics. Nat. Genet. Suppl. 32: 526-532.

McHugh, T.E., Atkins, W.M., Racha, J.K., Kunze, K.L., and Eaton, D.L. 1996. Binding of aflatoxin-glutathione conjugate to mouse glutathione S-transferase A3-3 is saturated at only one ligand per dimer. J. Biol. Chem. 271: 27470-27474.

Michalet, X., Pinaud, F.F., Bentolila, L.A., Tsay, J.M., Doose, S., Li, J.J., Sundaresan, G., Wu, A.M., Gambhir, S.S., and Weiss, S. 2005. Quantum dots for live cells, in vivo imaging, and diagnostics. Science 307: 538-544.

Miyamoto-Sato, E., Nemoto, N., Kobayashi, K., and Yanagawa, H. 2000. Specific bonding of puromycin to full-length protein at the C-terminus. Nucleic Acids Res. 28: 1176-1182.

Murakoshi, H., Iino, R., Kobayashi, T., Fujiwara, T., Ohshima, C., Yoshimura, A., and Kusumi, A. 2004. Single-molecule imaging analysis of Ras activation in living cells. Proc. Natl. Acad. Sci. 101: 7317-7322.

Nemoto, N., Miyamoto-Sato, E., and Yanagawa, H. 1999. Fluorescence labeling of C-terminus of proteins with a puromycin analogue in cell-free translation systems. FEBS Lett. 462: 43-46.

Okamoto, T., Suzuki, T., and Yamamoto, N. 2000. Microarray fabrication with covalent attachment of DNA using bubble jet technology. Nat. Biotechnol. 18: 438-441.

Paweletz, C.P., Charboneau, L., Bichsel, V.E., Simone, N.L., Chen, T., Gillespie, J.W., Emmert-Buck, M.R., Roth, M.J., Petricoin III, E.F., and Liotta, L.A. 2001. Reverse phase protein microarrays which capture disease progression show activation of pro-survival pathways at the cancer invasion front. Oncogene. 20: 1981-1989.

\section{Genome Research}

www.genome.org 
Microbead array for molecular interaction analysis

Pellois, J.P., Zhou, X., Srivannavit, O., Zhou, T., Gulari, E., and Gao, X. 2002. Individually addressable parallel peptide synthesis on microchips. Nat. Biotechnol. 20: 922-926.

Ramachandran, N., Hainsworth, E., Bhullar, B., Eisenstein, S., Rosen, B., Lau, A.Y., Walte, J.C., and LaBaer, J. 2004. Self-assembling protein microarrays. Science 305: 86-90.

Reboul, J., Vaglio, P., Rual, J.-F., Lamesch, P., Martinez, M., Armstrong, C.M., Li, S., Jacotot, L., Bertin, N., Janky, R., et al. 2003. C. elegans ORFeome version 1.1: Experimental verification of the genome annotation and resource for proteome-scale protein expression. Nat Genet. 34: 35-41.

Rhodes, D.R., Barrette, T.R., Rubin, M.A., Ghosh, D., and Chinnaiyan, A.M. 2002. Meta-analysis of microarrays: Interstudy validation of gene expression profiles reveals pathway dysregulation in prostate cancer. Cancer Res. 62: 4427-4433.

Sako, Y., Minoguchi, S., and Yanagida, T. 2000. Single-molecule imaging of EGFR signalling on the surface of living cells. Nat. Cell Biol. 2: $168-172$.

Thorsen, T., Maerkl, S.J., and Quake, S.R. 2002. Microfluidic large-scale integration. Science 298: 580-584.

Vaglio, P., Lamesch, P., Reboul, J., Rual, J.-F., Martinez, M., Hill, D., and Vidal, M. 2003. WorfDB: The Caenorhabditis elegans ORFeome database. Nucleic Acids Res. 31: 237-240.

Wang, J., Bauman, S., and Colman, R.F. 2000. Probing subunit interactions in $\alpha$ class rat liver glutathione S-transferase with the photoaffinity labeled glutathionyl S-[4-(succinimidyl) benzophenone]. J. Biol. Chem. 275: 5493-5503.

Wang, J.K., Li, T.X., Bai, Y.F., and Lu, Z.H. 2003. Evaluating the binding affinities of NF-кB p50 homodimer to the wild-type and single-nucleotide mutant Ig-кB sites by the unimolecular dsDNA microarray. Anal. Biochem. 316: 192-201.

Wang, M.M, Tu, E., Raymmond, D.E., Yang, J.M., Zhang, H., Hagen, N., Dees, B., Mercer, E.M., Forster, A.H., Kariv, I., et al. 2005. Microfluidic sorting of mammalian cells by optical force switching. Nat. Biotechnol. 23: 83-87.

Weng, S., Gu, K., Hammond, P.W., Lohse, P., Rise, C., Wagner, R.W. Wright, M.C., and Kuimelis, R.G. 2002. Generating addressable protein microarrays with PROfusion ${ }^{\mathrm{TM}}$ covalent mRNA-protein fusion technology. Proteomics 2: 48-57.

Zheng, D., Constantinidou, C., Hobman, J.L., and Minchin, S.D. 2004. Identification of the CRP regulon using in vitro and in vivo transcriptional profiling. Nucleic Acids Res. 32: 5874-5893.

Zhu, H., Bilgin, M., Bangham, R., Hall, D., Casamayor, A., Bertone, P., Lan, N., Jansen, R., Bidlingmaier, S., Houfek, T., et al. 2001. Global analysis of protein activities using proteome chips. Science 293: 2101-2105.

Received June 6, 2005; accepted in revised form August 23, 2005. 


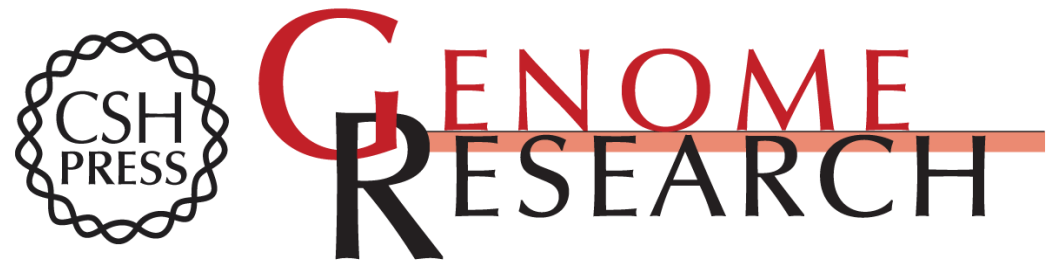

\section{Development of a microscopic platform for real-time monitoring of biomolecular interactions}

Yasuhiro Sasuga, Tomomi Tani, Masahito Hayashi, et al.

Genome Res. 2006 16: 132-139

Access the most recent version at doi:10.1101/gr.4235806

Supplemental Material

References License

Email Alerting Service
http://genome.cshlp.org/content/suppl/2005/12/13/gr.4235806.DC1

This article cites 41 articles, 16 of which can be accessed free at: http://genome.cshlp.org/content/16/1/132.full.html\#ref-list-1

Receive free email alerts when new articles cite this article - sign up in the box at the top right corner of the article or click here.

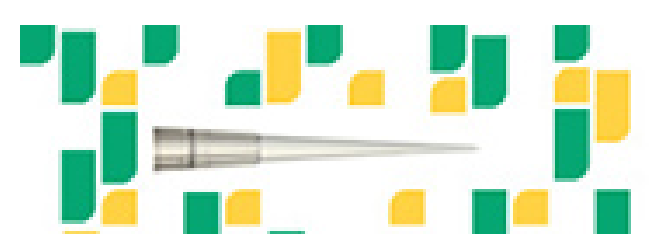

To subscribe to Genome Research go to: https://genome.cshlp.org/subscriptions 